\title{
Chapter 2 \\ Overview of Hometown Tax Donation and the Challenge It Poses to Municipal Administration-Paradigm Shift in Municipal Administration: Incorporating Management Perspectives

Keywords Hometown Tax Donation · AIDA · Tax credit · Tax return · Gifts

\subsection{Overview of Hometown Tax Donation}

Hometown Tax Donation is a system that enables citizens to donate to prefectures or municipalities of their choice. Donations are subject to tax credits, with donors essentially receiving a cashback for any amount donated exceeding 2000 yen in the form of inhabitant tax credit and income tax return. For instance, if a resident of Tokyo donates 10,000 yen to one's hometown municipality, the resident will pay 8000 yen less inhabitant tax the following fiscal year. Thus, the system enables donating 10,000 yen to one's hometown with an actual cash outflow of only 2000 yen. Individuals who are originally from rural areas but now work in Tokyo have limited means to repay their hometown, but Hometown Tax Donation enables one to do so. Donations can be made not only to one's hometown but to any municipality; for instance, municipalities one is associated with in some way, has enjoyed visiting, or wants to support for disaster relief.

When making a Hometown Tax Donation, the maximum amount donated subject to receiving tax credit and tax return benefits (cashback) is $20 \%$ of one's inhabitant tax amount. (This upper limit was 10\% until March 2015, but was raised to $20 \%$ in April 2015 accompanying a tax reform aimed at promoting the system.) Since the donor will pay less inhabitant tax in the following fiscal year, the donor's residential municipality will end up with less tax revenue. Without this upper limit, urban municipalities will face the risk of a bottomless drop in tax revenue.

This chapter is based on part of a study by Hoda and Yasui (2017) with some revisions and additions. 


\subsubsection{Backdrop and History Behind the Creation of Hometown Tax Donation}

According to the Ministry of Internal Affairs and Communications (MIC) which oversees Hometown Tax Donation, the following discussions prompted the creation of Hometown Tax Donation. Many people are born in rural areas and grow up receiving various public services from that municipality, including medical care and education; however, once they move to urban areas for higher education or to work, they end up paying tax to that city. Consequently, while the urban municipality earns tax revenue, the municipality where one was born and raised does not. Hence, concern was raised that "there should be a system enabling those currently living in cities to voluntarily pay some tax to one's 'hometown' where one was nurtured" (source: Report by Hometown Tax Donation Study Group), and the system was established after numerous discussions and deliberations.

The Hometown Tax Donation Study Group met nine times between June and October of 2007 at the MIC. Based on the discussions held, the Local Tax Act was revised, and Hometown Tax Donation was launched on April 30, 2008.

The significance of and philosophy behind this system, according to the MIC, is (1) providing opportunities for tax payers to consider how their tax is used; (2) enabling individuals to endorse the region of their choice; and (3) urging municipalities to publicize their initiatives in order to capture Hometown Tax Donations, thereby promoting competition among municipalities.

\subsubsection{Virtual Transfer of a Portion of Tax Between Regions}

In short, Hometown Tax Donation is a system that enables citizens to select where to pay a portion of their tax. However, since individuals' taxes cannot be split by will or on compulsion, citizens donate to regions of their choice and receive a cashback for most of the amount donated in the form of tax credits and tax returns so that one's actual cash outflow is kept to a minimum. In effect, citizens are selecting where to pay a portion of their tax.

Those who hear about this system for the first time are often surprised by disbelief, so I will present an example case. If a resident of Kobe City makes a Hometown Tax Donation of 40,000 yen to Otaru City in Hokkaido Prefecture, the resident will receive an inhabitant tax credit of 38,000 yen (in some cases, this cashback will also consist of income tax return), so one's actual cash outflow is only 2000 yen. Economically, Kobe City's tax revenue will decrease by 38,000 yen, while Otaru City's revenue will increase by 40,000, resulting in virtual transfer of tax between regions. Figure 2.1 shows the economic burden of individuals, and the economic effect on the donor's residential municipality, the national government, and the municipality receiving 


\section{Economic Effect on Individuals}

\begin{tabular}{|c|c|c|}
\hline \multicolumn{3}{|c|}{ When individual does not make a Hometown Tax Donation } \\
\hline & Individual's total actual payment & -20 \\
\hline \multicolumn{3}{|c|}{ When individual makes a Hometown Tax Donation } \\
\hline a & Inhabitant and income tax payment to residential municipality and country & -20 \\
\hline $\mathrm{b}$ & Hometown tax donation to municipality of choice & -4 \\
\hline $\mathrm{c}$ & Inhabitant tax credit and income tax return from residential municipality & 3.8 \\
\hline $\mathrm{d}=\mathrm{a}+\mathrm{b}+\mathrm{c}$ & Individual's total actual payment & -20.2 \\
\hline
\end{tabular}

\section{Economic Effect on Municipalities}

When resident does not make a Hometown Tax Donation Inhabitant and income tax received by residential municipality and country Amount received by residential municipality and country

20

20

When resident makes a Hometown Tax Donation

e Amount received by municipality receiving Hometown Tax Dontions 4

f Inhabitant and income tax received by residential municipality and country 20

g Tax credit and return to individuals from residential municipality and country $\quad-3.8$

$\mathrm{h}=\mathrm{f}+\mathrm{g} \quad$ Actual amount received by residential municipality and country $\quad \mathbf{1 6 . 2}$

$\mathrm{i}=\mathrm{e}+\mathrm{h} \quad$ Total amount received by all municipalities and country

Fig. 2.1 Economic Effect on Individuals and Municipalities With and Without Hometown Tax Donations. Source Created by the author. Note The model is simplified. Values are shown in units of 10,000 yen. [b] is calculated as $20 \%$ of [a] (since the maximum amount donated subject to receiving tax credit benefits is set to $20 \%$ of one's inhabitant tax amount). [c] is the amount deducting 2000 yen from [b] 40,000 yen

Hometown Tax Donation. (In the case above, Kobe City is the donor's residential municipality, while Otaru City, Hokkaido Prefecture, is the municipality receiving donations.)

\subsubsection{Dispute Between Rural Areas Receiving Benefits and Urban Areas Facing Revenue Outflow}

Based on the above, although tax is essentially transferred between regions, one can speculate that Hometown Tax Donation is a beneficial tool for rural areas facing drastic deterioration. Furthermore, as the amount of [i] in Fig. 2.1 shows, the revenue of the country as a whole increase from 200,000 yen to 202,000 yen, so the country's revenue also seems to benefit. In the meantime, some regions (especially urban municipalities) are largely affected by the decrease in inhabitant tax revenue due to tax credits from Hometown Tax Donation. In the fiscal year ended March 2021, the decrease in inhabitant tax was 14.4 billion yen in Yokohama City, 8.5 billion yen in Nagoya City, 7.1 billion yen in Osaka City, 6.3 billion yen in Kawasaki City, and 4.9 billion yen in Setagaya Ward. The outflow of inhabitant tax of all municipalities in Tokyo Prefecture totaled 85.9 billion yen. When tax revenue decreases, $75 \%$ of 
the decrease is compensated by increased local allocation tax grants in the following fiscal year (in the case of Yokohama City), but for municipalities that are not eligible to local allocation tax grants, such as Kawasaki City or the 23 special wards of Tokyo, inhabitant tax credit translates directly to a revenue decline. Therefore, not a few municipalities are opposed to Hometown Tax Donation, especially those in urban areas where tax revenue has declined because of the system. In fact, the 23 special wards of Tokyo announced a joint emergency statement on August 6, 2020, calling for revision of the system. While I will omit the details, the statement calls for alleviating the disadvantages for urban areas.

\subsection{4 "Gifts" in Hometown Tax Donation: A Core Driver of Regional Revitalization (The Focus of This Book)}

Meanwhile, Hometown Tax Donation has another feature which has fueled controversy surrounding the system as well as debates on the dispute between rural and urban areas; namely, that it has become increasingly common for municipalities receiving donations to give donors reciprocal gifts equivalent to $30 \%$ of the amount donated.

For municipalities currently facing a decline in population and tax revenue, individuals who make Hometown Tax Donations are extremely valuable. Naturally, municipalities will wish to express their gratitude or have donors know more about the municipality. Municipalities initially expressed their gratitude in various ways, with some sending thank you notes and others sending local specialties as reciprocal gifts. Local specialties were sent out in a similar vein as sharing home-grown products to neighbors, as is common in rural areas. This is how municipalities initially began to thank donors.

In the marketing world, the principle of AIDA is a well-known model describing consumers' actions till purchase. When applying this model to municipalities, municipalities draw "attention" using gifts, raise consumers' "interest" in the town through such gifts, drive consumers' "desire" to visit the town or purchase local specialties, and finally induce "actions" such as purchasing goods or visiting the town. By sending gifts, municipalities are essentially conducting marketing.

Once individuals making Hometown Tax Donations find out about such gifts, they will want to donate to municipalities that give out attractive gifts. In fact, between 2016 and 2019, the race among municipalities to provide more pricey or lavish gifts become an issue, sparking much criticism toward Hometown Tax Donation. To ensure soundness of the system, the law was revised in 2019. Currently, the maximum value of gifts is set to $30 \%$ of the amount donated, and to $50 \%$ when including packing, delivery and other processing expenses. Following this law revision, and as of October 2020, competition to provide excessive gifts among municipalities has subsided, and focus has been shifting toward how each municipality can effectively use funds procured through Hometown Tax Donation. Also, since differentiation 
based on gifts is becoming difficult, municipalities are urged to make greater efforts, including publicizing how donations will be used.

Figure 2.2 shows the overall flow of Hometown Tax Donation including gifts.

Based on Figs. 2.1 and 2.2, Fig. 2.3 summarizes the economic effect on individual donors.

In part, since the system was introduced by various media as a "bargain" system, the Hometown Tax Donation market has expanded, with the total amount of Hometown Tax Donation in the fiscal year ended March 2020 reaching 487.5 billion yen (a decrease of $4.1 \%$ YoY), and the number of donors in 2019 (from January to December) reaching 4060,000 (an increase of 2.7\% YoY). (Both figures announced by the MIC. The number of donors represents those who received tax credits after making Hometown Tax Donations, so the actual number may be higher). The shrinking market size based on amount donated is due to subsiding competition in providing more pricey or valuable gifts following law revisions, and when considered together with the gradual rise in number of donors, the Hometown Tax Market can be regarded as having entered a phase of stability (Fig. 2.4).

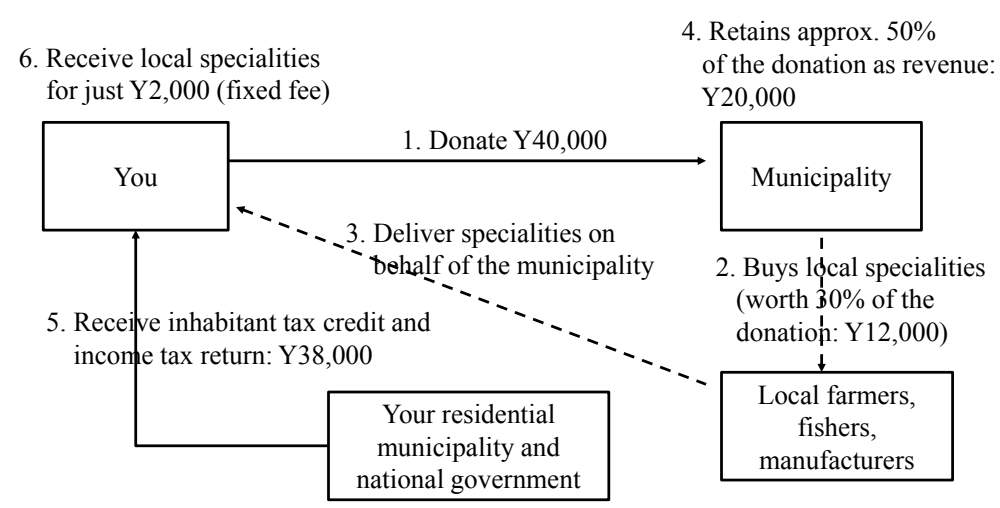

Your actual cash outflow is Y2,000, while receiving Y12,000 worth of local specialities in return.

Fig. 2.2 Overall flow of Hometown Tax Donation. Source From Hoda and Yasui (2017) with some revisions. Note Municipal revenue is shown as 50\% of amount donated in [4] assuming that the value of gifts is $30 \%$ of the amount donated, and packing, delivery and other processing expenses are $20 \%$

Fig. 2.3 Benefits for individuals making hometown tax donations \begin{tabular}{ll} 
Donation: & $-40,000$ yen \\
Tax cashback: & $+38,000$ yen \\
Reciprocal gift: Approx. & $+12,000$ yen \\
\hline Resulting benefit: Worth & $+10,000$ yen
\end{tabular} 


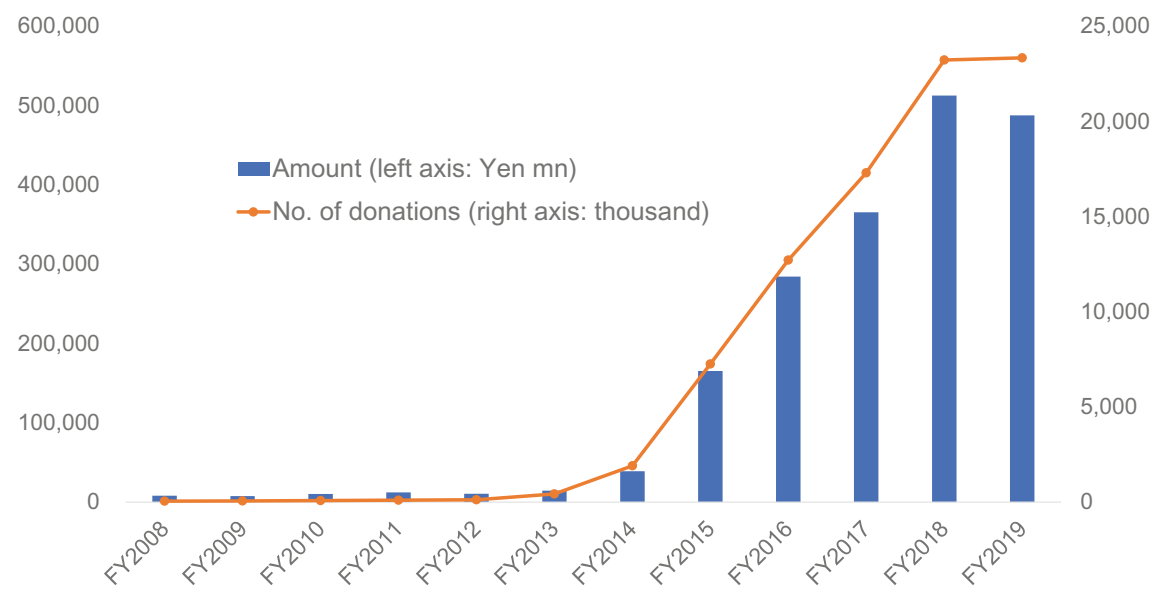

Fig. 2.4 Market size of Hometown Tax Donation. Source Created from data released by the MIC

\subsection{Paradigm Shift in Municipal Administration: From "Administration" to "Management"}

Hometown Tax Donation has contributed to municipalities, especially those in rural areas, by instilling the idea that municipalities must be managed rather than administered. Most importantly, it introduced the two perspectives of innovation and marketing to municipalities. Municipalities are discussed in the second chapter of Peter Drucker's "Management," a business management classic. Drucker explains that municipalities and companies can be distinguished by their orientation toward "goals" and "results." The goal for municipalities is to secure high budgets and implement large-scale projects, while companies seek efficiency by aiming to achieve results using low budgets. Once municipalities launch a large-scale project, they need to secure more budget to sustain the project. Such municipal activities involve neither innovation nor marketing. In this way, municipal administration is based on a completely different rationale from company management.

However, municipalities in need of money must now procure or produce their own funds instead of securing budgets from the national government. To do so, they must determine what their local capitals and strengths are, effectively promote and generate added value and innovativeness of such capitals, deploy marketing, and capture funds through purchases by non-locals. Ultimately, municipalities need to secure money by selling local goods and services, and this process is exactly the same as that of company management. 


\subsubsection{A Framework Where Funds Are Secured Through Excellent Marketing}

It was under such circumstances that Hometown Tax Donation was established. Municipalities will be able to receive donations if they are successfully selected by general consumers. This implies that municipalities need to skillfully market themselves. Marketing regional characteristics, donation usage, and the attractiveness of gifts (i.e., local specialties) becomes important. In other words, municipal administration is currently approaching a turning point in a shift toward municipal management. However, equity and fairness continue to be fundamental in terms of providing public services. Municipalities therefore cannot be managed completely like companies. Nonetheless, there is no denying the importance of management perspectives, since municipalities that incorporate management perspectives will capture more funds and be able to provide better public services. As such, one achievement of Hometown Tax Donation is that it has served to fortify the resilience of municipalities. Meanwhile, one can predict that some municipalities will be indifferent to such management perspectives and have difficulty obtaining funds. For such municipalities, Hometown Tax Donation will be a source or concern.

\subsubsection{Difficulty in Marketing, Specific to Municipalities}

Hometown Tax Donation is significant in that it has prompted municipalities to make an effort to market regional attractiveness. At the same time, it is hard for municipalities, of which there are over 1700, to single-handedly capture people and money from outside the region. Even for companies, marketing strategies are subject to daily trial and error, and yielding desirable results is difficult. Attempts by municipalities without experience in this area will likely end up being a waste of money and therefore inefficient. Differentiation is particularly difficult among municipalities. Companies can be differentiated with their products by category of industry; for example, Toyota produces automobiles, while Suntory produces beverages and food. In addition, the number of leading companies in each industry will most likely be fewer than 100 .

However, in the case of municipalities, there are no classifications like industries for companies, other than the distinction between urban or rural areas. This makes it even more difficult for municipalities to develop marketing strategies. One solution may be to implement PR activities with the greater region by collaborating with neighboring municipalities, rather than on their own. It is necessary for municipalities to consider more efficient ways as well as sharing expenses and benefits with neighboring municipalities, instead of keeping to themselves. 


\subsubsection{Future Investment-Uncharted Land for Municipalities}

In recent years, municipalities have been facing budget cuts on a yearly basis, and their tasks have been centered on discontinuing or aborting existing projects and thereby reducing costs, rather than starting something new. In other words, they have their hands full with sustaining current levels. I was impressed by a municipality personnel's comment that, contemplating the usage of Hometown Tax Donations was the first forward-looking task he had engaged in since starting to work for the local government. The process of investing, raising revenue, and creating the future is considered a given for companies, but will be unexplored territory for many municipalities. Municipalities should take on this challenge by drawing on successful cases of companies as well.

\subsubsection{Who Are Municipalities' Customers in Present Times?}

In conventional municipal administration, town residents would be considered the town's customers. As a matter of course, locals would pay inhabitant tax, and in return, receive regional services. However, for regions to aim for economic development amidst regional depopulation, they will need to capture people and capital from outside the region. This implies reaching out to non-locals as new customers. Generally, citizens believe that the local government should spend $100 \%$ of their resources for public services targeting locals, and local government personnel also take this for granted. Therefore, it is not easy for municipalities as well as residents to change their actions by defining non-locals as new customers. However, if able to capture such new customers, municipalities can expect an increase in regional revenue through Hometown Tax Donations, wider acknowledgement of the region through exposing local specialties to other regions as gifts, and an accompanying increase in associating and interacting populations. Such outcomes in turn will enable enhancing public services for locals. Whether municipalities can change their conception on municipal administration in this way (i.e., make a paradigm shift), will be the key to fostering municipal competitiveness (Fig. 2.5).

However, when trying to capture non-locals as new customers, the boundary will be subject to debate. For instance, if one town tries to increase the inflow of people, residents of neighboring municipalities will most likely be the easiest ones to make visits. People rarely visit a non-touristic municipality from afar. This means that a large portion of a municipality's new customers will be residents of neighboring ones, and this may lead to competition to win customers among neighboring municipalities. Competition to win customers is commonplace in company management. However, municipalities have specific geographical boundaries, and customers have naturally been restricted to those within such boundaries. Municipal administration 
Fig. 2.5 New composition of municipalities' customers. Source From Hoda and Yasui (2017)

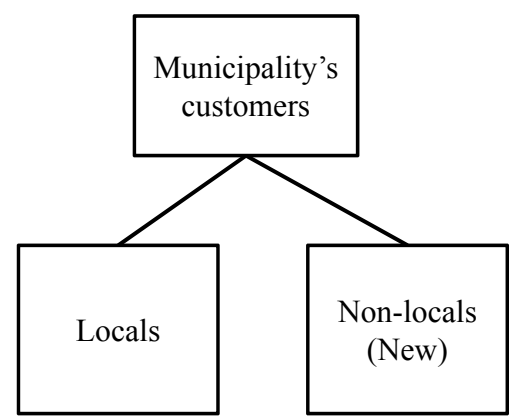

will become somewhat complex if a potential customer base is created outside this boundary. I will revisit such issues in Chap. 6.

\subsection{Institutional Issues Involved in Hometown Tax Donation: Total and Partial Optimization}

Echoing the aforementioned discussion on competition to win customers among municipalities, optimal solutions may differ between the standpoint of the national government and each municipality. While I omit the details, there was a lawsuit between Izumisano City in Osaka Prefecture and the national government regarding Hometown Tax Donation. Previously, there were no explicit legal regulations for gifts, and instead, a guideline was released in the form of a notice by the Minister for MIC. Izumisano City basically ignored this guideline and collected massive donations by providing more attractive gifts than other municipalities. In response to Izumisano City's disregard of the guideline, the national government excluded the city from the Hometown Tax Donation system in 2019, whereby, the city filed a lawsuit against the national government.

Explaining the details and arguments of both sides is not the intent here. However, I would like to point out that, frankly speaking, for municipalities to survive, collecting every penny (or yen) possible in donations will make locals happy and be considered the right behavior for mayors or municipal personnel, even if this involves causing inconvenience to the national government or other municipalities.

If national growth is rapid, tax revenue will increase, and revenue source of all municipalities would also rise. However, in the current state of faltering growth, over 1700 municipalities must compete for people, goods and capital. Hometown Tax Donation more or less fuels this competition. As mentioned, the amount donated subject to receiving tax credit benefits is set to $20 \%$ of one's inhabitant tax amount, so the system can be interpreted as a message from the national government stating that "municipalities nationwide should compete with one another to win $20 \%$ of all national residents' inhabitant tax. To do so, municipalities must endeavor to promote regional attractiveness and implement marketing activities." 
In the past, municipalities took uniform actions under rules set forth by the national government. Now that we face population decline and deterioration of rural areas, municipalities need to find their own optimal solutions while considering the direction indicated by the country. This implies that intense competition between municipalities may occur going forward. If one likens a municipality to a company, this is exactly the same scenario that takes place in company management. Like companies, municipalities can also reinforce their strengths by collaborating with other municipalities. Collaborating with the greater region will enable sharing each other's resources, thereby generating a larger positive impact on regional PR activities and local industries.

\subsection{Various Discussions Regarding Hometown Tax Donations}

As mentioned, although Hometown Tax Donation is defined as a donation, it can be interpreted as transfer of individuals' inhabitant tax to another municipality. Also, since donors receive gifts in addition to a tax credit, some liken the system to online shopping using tax. This should have supportive effects on regional economies. As another potential benefit, since the attractiveness of gifts influences one's choice of where to donate to, gift providers' mutual efforts to raise attractiveness of their products may contribute to enhanced regional business capabilities.

Meanwhile, municipalities that produce popular gifts (e.g., rice, seafood and meat) are in an advantageous position. Admittedly, the attractiveness of gifts is not everything - as will be mentioned in Chap. 7, the scheme of Hometown Tax Donation based on civic crowdfunding has also been gaining ground recently, where municipalities seek to win widespread empathy by specifying the usage of donations in advancenonetheless, gifts significantly influence consumers' selections. Municipalities with scarce selection of gifts will naturally be placed at a disadvantage.

Municipalities of the donor' $s$ residence will be in an even more disadvantaged position since their inhabitant tax will be reduced. There is strong criticism regarding this aspect, especially from tax experts, that Hometown Tax Donation distorts the principle of tax. Particularly, in view of the benefit principle of taxation, Hometown Tax Donation deviates from the principle that tax payers and beneficiaries should be the same. The more residents in one region make Hometown Tax Donations, the more the quality and quantity of public service may decline in that municipality. Contrarily, the quality and quantity of public services in the municipality receiving donations may rise, and there are views that this only adds fuel to the zero-sum game. Some are also of the opinion that the gap in tax revenue between urban and rural areas is already compensated by local allocation tax grants, and that this break-even between regions should not be disrupted.

This book leaves out such debates about the pros and cons of the system itself, and instead presents several analyses from the viewpoint of how this system should be 
used effectively to drive regional revitalization. I will present these analyses in order in the following chapters. Chapters 3 and 4 present the system's impact on incubation of local businesses through gifts and the ensuing implications for generating regional entrepreneurship. If such impacts are identified, they may serve as inspirations for policies necessary in regional revitalization, regardless of whether the system continues to exist or not. Increasing associating and interacting populations will be the key to regional revitalization and development, and Chap. 5 explores whether Hometown Tax Donation prompts regional revitalization and incubation through collaboration between municipalities and regional financial institutions. Chapter 6 examines the elements necessary to increase associating and interacting populations by referring to Hometown Tax Donation cases. Based on a survey research targeting regional financial institutions, I will search for clues for partnership in regional revitalization between local businesses, municipalities and financial institutions. Chapter 7 envisions the future of regional management by summarizing the current state of civic crowdfunding.

\section{Reference}

Hoda T, Yasui T (2017) Theories and practices of hometown tax donation (In Japanese). Sendenkaigi Co., Ltd./Publishing Department of The Graduate School of Project Design

Open Access This chapter is licensed under the terms of the Creative Commons AttributionNonCommercial-NoDerivatives 4.0 International License (http://creativecommons.org/licenses/bync-nd/4.0/), which permits any noncommercial use, sharing, distribution and reproduction in any medium or format, as long as you give appropriate credit to the original author(s) and the source, provide a link to the Creative Commons license and indicate if you modified the licensed material. You do not have permission under this license to share adapted material derived from this chapter or parts of it.

The images or other third party material in this chapter are included in the chapter's Creative Commons license, unless indicated otherwise in a credit line to the material. If material is not included in the chapter's Creative Commons license and your intended use is not permitted by statutory regulation or exceeds the permitted use, you will need to obtain permission directly from the copyright holder.

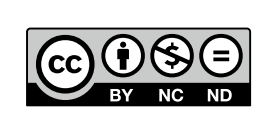

